\title{
COVID-19 Update: Saskatchewan intensive care crisis, new vaccine safety data, and pushback on health worker mandates
}

\author{
— Cite as: CMAJ 2021 November 15;193:E1743-4. doi: 10.1503/cmaj.1095973
}

Posted on cmajnews.com on October 28, 2021

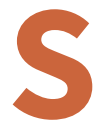

askatchewan Premier Scott Moe said he would not order any lockdowns or public health measures that would close businesses to curb the spread of SARS-CoV-2 because he does not think it is fair to restrict people's activities.

The Oct. 25 announcement came as COVID-19 hospitalizations are pushing the province's intensive care capacity to the limit.

In October, Saskatchewan had more intensive care patients per capita than any other province at any point in the pandemic. Without additional public health measures, provincial modelling showed that there could be more than 200 patients with COVID-19 in intensive care by Jan. 1 more than double capacity.

The Saskatchewan Health Authority warned Moe's government in June about the risk of a fall surge in hospitalizations, and trends in admissions have closely tracked those predictions. Even so, the province lifted pandemic measures in July and didn't reinstate any precautions until mid-September, when the government reintroduced a mask mandate and announced a proof-of-vaccination program.

On Twitter, Canadian Medical Association president Dr. Katharine Smart decried Moe's inaction and "continued attempts at gaslighting." Previously, Smart called on Saskatchewan's government to reinstate strict public health measures, including circuit breaker lockdowns, noting that further delays are "simply not acceptable."

In the meantime, Saskatchewan is continuing to transfer intensive care patients to Ontario and will receive additional critical care nurses from the military.
The Saskatchewan Health Authority is also hiring 32 critical care nurses and training 39 nursing students to work in intensive care.

\section{In other COVID-19 news:}

- Vaccination against SARS-CoV-2 does not increase the risk of miscarriage in early pregnancy, according to research in the New England Journal of Medicine. Researchers analyzed data on firsttrimester pregnancies in Norway and compared people who miscarried with those who did not and whether they were more likely to have recently received a SARS-CoV-2 vaccine. Accounting for underlying health conditions and other patient characteristics, they found no correlation between vaccination and miscarriage.

- Infection with SARS-CoV-2 poses a greater risk of rare neurological conditions than vaccination against the virus, according to a study in Nature Medicine. Researchers looked at the health records of 32 million people in England to analyze the risk of developing Bell's palsy, Guillain-Barré syndrome and other rare conditions after testing positive for SARS-CoV-2 versus receiving Pfizer or AstraZeneca SARSCoV-2 vaccines. Although vaccination against SARS-CoV-2 slightly increased the risk of some conditions, infection with the virus posed a substantially higher risk of all neurological complications examined.

- Four physicians are threatening to sue Alberta Health Services (AHS) over a policy requiring workers to be fully vaccinated against COVID-19 by Nov. 30 .
In their statement of claim, the doctors allege that the policy violates their right to bodily autonomy and breaches their confidentiality because a worker's vaccine status will be evident if they have to go on leave. Such lawsuits are unlikely to be successful, according to University of Calgary law professor Lorian Hardcastle. "The allegations... are quite confusing because, of course, nobody is forcing treatment on anyone." So far, $94 \%$ of AHS employees and physicians are fully vaccinated.

- Quebec may again postpone its deadline for health care workers to be fully vaccinated against SARS-CoV-2. The province previously extended the original Oct. 15 deadline to Nov. 15 because of concerns about staffing shortages. Premier François Legault said a further extension may be necessary for the same reason. More than 19600 health care workers in Quebec are not fully vaccinated. The province is seeking to recruit 4000 nurses to the public health system, including by offering up to $\$ 18000$ in bonuses.

- Alberta has asked the federal government for a supply of the Johnson \& Johnson SARS-CoV-2 vaccine, but it's unclear when the shots will be available. Provincial officials hope that offering the single-shot, viral vector vaccine as an alternative to available mRNA shots will improve immunization rates in some areas of rural Alberta. Premier Jason Kenney said he has heard from people who are hesitant to get an mRNA vaccine but would consider receiving the Johnson \& Johnson shot. 
- Moderna said a half-dose of its SARSCoV-2 vaccine is safe and effective in children aged 6-11, according to a study of 4753 children. The most common adverse effects in young children, like in adults, included fatigue, headache, fever and injection-site pain. The study was too small to pick up any extremely rare adverse effects. Moderna plans to submit the data to the United States Food and Drug Administration and other regulators soon. Health Canada approved the company's vaccine for teens aged 12-17 at the end of August.

- The pharmaceutical company Merck is seeking authorization from the European Medicines Agency for its SARSCoV-2 antiviral treatment. The company submitted an approval request to the U.S. Food and Drug Administration earlier in October. If approved, the pill would be the first treatment for COVID19 not administered parenterally. Merck has reported that the treatment reduces hospitalizations and deaths by half in patients with early COVID-19 symptoms.

Abigail Cukier, Hamilton, Ont.

Content licence: This is an Open Access article distributed in accordance with the terms of the Creative Commons Attribution (CC BY-NC-ND 4.0) licence, which permits use, distribution and reproduction in any medium, provided that the original publication is properly cited, the use is noncommercial (i.e., research or educational use), and no modifications or adaptations are made. See: https://creativecommons.org/ licenses/by-nc-nd/4.0/ 